\title{
NETWORK FORM OF INTERUNIVERSITY COOPERATION AS A WAY OF IMPLEMENTING VIRTUAL ACADEMIC MOBILITY
}

\author{
Olga B. Shestakova ${ }^{1}$, Inna V. Kazantseva ${ }^{2}$, Tatyana I. Zaburdaeva ${ }^{3}$, \\ Olga A. Rtisheva ${ }^{4}$ \\ ${ }^{1}$ Prof., Mari State University, Russia, shobor@bk.ru \\ ${ }^{2}$ Prof., Mari State University, Russia, inna-kazanceva@ yandex.ru \\ ${ }^{3}$ Prof., Mari State University, Russia, tanja-zab@yandex.ru \\ ${ }^{4}$ Prof., State Pedagogical University Uljanovsk, Russia, rtisheva.oa@mail.ru
}

\begin{abstract}
The article is devoted to the development of network forms of interuniversity cooperation that is one of the vital problems of higher education in Russia. The article describes theoretical basis for updating the elements (training modules) that already exist, as well as for developing methodological support and networking model of cooperation of partner universities. The necessity of using network forms in the activities of universities is emphasized in "Education Act of the Russian Federation" (dated 29.12.2012). The current process of integration requires active and successful ways of network cooperation among universities in different fields (scientific, educational, and social). The algorithm description of the educational activities according to the implemented educational programs at the Departments of the partner universities appear promising and relevant, and is able to help activate the virtual academic mobility in accordance with the new objectives in education and new stages in the development of science. The research is based on the cooperation of Mari State University and Ulyanovsk State Pedagogical University named after I.N. Ulyanov".

The project presupposes the following: interdisciplinary, social and philosophical understanding of the phenomenon under study, the outcome of which will be clear theoretical and methodological foundations for analyzing and designing models of partnership networks with the participation of universities; optimization of activities in the social network, evaluating the effectiveness and predicting the results of partnership networking of universities.

The partner universities stated in the project have the necessary facilities for carrying out educational process and scientific co-operation using on-line technologies as a way of implementing virtual academic mobility.
\end{abstract}

Keywords: Network form, virtual academic mobility, curriculum, model

\section{INTRODUCTION}

The peculiar feature of the modern level of the development of higher education in Russia is its structural modernization aimed at the tasks formulated in the the Concept of long-term socio-economic development of the Russian Federation for the period until 2020, and the State Program of the Russian Federation 
"Development of Education" for the period of 2013 -2020. The increasing global competition, the growing role of innovation in the socio-economic development requires turning the system of education into the platform for working out innovation products and training specialists of a new kind, having a high intelligence, professional competences, and the capacity of creative activity. Modern higher educational establishments are to use different forms and technologies of educational, scientific-research, and innovation activities, following the best domestic and foreign models, to provide the opportunity of getting education through the whole life, using flexible (module) trajectory pg acquiring new competences (Zaburdaeva \& Serebryakova \& Kazantseva \& Kolyago \& Ivanova 2015).

The necessity of using network forms in the activities of universities is emphasized in "Education Act of the Russian Federation" (dated 29.12.2012). The current process of integration requires active and successful ways of network cooperation among universities in different fields (academic, educational, professional, and social).

The key activities aimed at promotion of universities in the rankings include realization of joint educational programs with other universities which include inviting the leading experts for conducting classes and carrying out joint researches, developing academic mobility of students and teachers of partner universities.

The network form of educational programs makes it possible for universities to:

- introduce new educational programs in cooperation with the leading Russian and foreign universities and scientific organizations;

- implement programs of domestic and international academic mobility of researchers and teachers in the form of internships, advanced training, qualification improvement, and other forms;

- exchange partner-universities students for the realization of joint educational programs.

Positioning the university on the educational services market involves the following: creating the image of a competitive university as a member of networking; using complementary assets of universities - network partners; implementing network educational programs, and opening basic departments (and other institutions) as the university brands which confirm its leading role in the education system .of Russia.

\section{OPINIONS AND DISCUSSION}

Networking is the new trend in education. The analysis of the current state of research shows lack of theoretical development of this type of inter-University integration.

Nowadays the demand for individual learning program is increasing. The network form of implementing educational programs extends the awareness of students about the available educational and other resources, and allows them to make a conscious choice of their own educational trajectory, which increases their learning motivation, their responsibility for achieving the results.

The realization of the idea of networking is determined by the plan of actions approved by the order of the Government of the Russian Federation № 2620 dated by 30.12.2012, the goal of which is to increase the efficiency and quality of services in the field of professional training. Besides the Ministry of Education of the Russian Federation supports and encourages the network form of realizing educational programs. This network has been included into the list of indicators for monitoring the effectiveness of universities of the Russian Federation.

Consolidation of educational and scientific resources of partner organizations participating in networking allows them to optimize and minimize training expenses, to attract the leading educational institutions to joint activities, which will help to improve the quality of education and to accumulate the best experience in the field of vocational training, as well as to update educational programs in accordance with the level and peculiarities of providing the resources for real professional activities.

Participating in networking universities have some advantages, the main of which are education quality, working efficiency, competitive abilities of the university and of the educational programs, openness, mobility, positioning of universities at the education market.

One of the necessary conditions for organizing network interaction of educational institutions is legislative basis of regulating the legal relations of the network participants.

Regulatory documents in this field touch upon various aspects of network interaction. So, the Education Act outlines the range of potential participants of networking, including:

- educational organizations; 
- organizations involved in educational activities;

- other (resource) organizations having the necessary resources for conducting training, practice, etc.

The Order of the Ministry of Education of the Russian Federation № 499 determines the levels of education at which networking can be implemented. According to the Order, the network form is valid for all levels of education, with the most flexibility provided to networking at the level of postgraduate training.

The Bologna Declaration gives the definition of a "joint diploma" which refers to a certificate of higher education (qualification, degree), issued jointly by two or more institutions of higher education on the basis of a joint training program. A "joint diploma" may be given in the form of a separate document in addition to one or more national university (college) diplomas; in the form of a general single document given by the higher education institutions providing the course of training on this educational program, which is not followed by giving national diplomas; or in the form of one or more national diplomas at the same time to confirm qualification received.

Some Russian universities have the experience of interacting in the form of networking. The analysis of the experience is reflected in a number of analytical publications, stating the advantages and the main problems of the network form of implementing educational programs.

Vesna E. B. and Guseva A. I. describe the models of interaction between organizations while realizing educational programs in the network form on the basis of the National research nuclear University "MIPhl". Starygina N. N. shares her experience of organizing network interaction at the Volga State University of Technology. Minurova S. A. (Ural State Teacher-Training University) gives the results of the network cooperation of the University and educational institutions of the region in solving problems of modernization of psychological-pedagogical education. The article by Alexandrova $\mathrm{N}$. is devoted to the analysis of organizing network interaction of the type "school-university" by means of distance learning technologies.

Different classifications of networking can be found in a number of studies (by Remorenko I.M., by Starygina N.N.). The following types are differentiated:

- forms of cooperation: network projects (associations, assemblies), network educational events (competitions, contests), interaction between educational institutions;

- interaction levels: the level of information, the level of distributing responsibilities, the level of developing social and educational standards, the level of resource sharing between educational institutions, the level of implementing educational programs;

- types of networking: cluster and point.

- Analyzing the experience in the field of network interaction, the authors point out both its advantages and the problems they have faced. Ryabova N.V. mentions the following problems of interaction in the field of network management:

- decentralization (horizontal relations predominate over vertical relations);

- partial leadership (each subject can be a leader in one area of activity, and only a performer or a participant in another area);

- broad specialization (it is necessary to deals with bordering issues rather than with narrow professional ones);

- Informal relationships (the network participants have both formal professional relations, and the socalled club relations).

The analysis of the networking typological features shows that the model focused on implementing virtual academic mobility within one area of training is the most acceptable in the system of higher education .

Networking requires special conditions that are primarily connected with the content and technologies of the organized interaction. The relationship of the two components of this process- the content and resources (both material and technical, and pedagogical) should be take into account This approach is based on the idea of systematics, involving the relationship and interdependence of various sides and aspects of the phenomenon under consideration (Andreeva \& Glizerina \& Kolomiets \& Kurochkina \& Maltseva \& Shestakova 2015).

All the parts of the networking process build a coherent whole. Each part is the basis for the following one. Such an approach to solving problems is the most relevant in the light of modern principles and methods of scientific research. 
In this regard, there is a need to update the content of existing elements - training modules (Zaburdaeva \& Kazantseva \& Kolyago \& Shestakova \& Hammelmann 2016), as well as to develop a new algorithm (conditions and procedure) of implementing educational activities on the ongoing educational programs at the faculties of foreign languages of the partner universities, which is to contribute to the process of intensifying virtual academic mobility in accordance with the new aims of education and new stages the development of science.

If we accept the fact that the social and human sciences have developed certain theoretical assumptions that determine the basic conditions for studying different forms of networking of the university and their impact on the effectiveness of the innovation activities of the whole scientific and educational complex that characterizes modern universities, then we should point out the following ones. Firstly, it is a sociological network theory revealing the regularities of developing and functioning of social networks. Secondly, it is the actively developing theory of practice studying the basic practices as catalysts and stimuli of social processes. Thirdly, it is the experience of constructing theoretical images of social phenomena. And finally, it is the economic basis that allows to evaluate the innovative activities of a faculty / a university in terms of its efficiency and effectiveness, as well as to model the relationship between the network activities and the innovation indicators.

The complex research of the networking process is aimed at finding out general, special and individual patterns of these activities.

In our study we rely on the following methodological principles of comprehensive studies:

1. The principle of objectivity requiring a thorough account of the factors generating this or that phenomenon, the conditions, the adequacy of research approaches and tools to obtain true knowledge about the object; it is supposed to exclude subjectivity, one-sidedness and bias in selecting and evaluating facts.

This principle requires evidence of all conclusions, validity both of assumptions and of each step of the research.

2. The principle of science, comprising:

- compliance of the content of education to the level of modern science;

- creation of true ideas of the general methods of scientific comprehension;

- demonstration of the most important principles of the process of comprehension (knowledge of the theory, its elements, structure and functions).

3. The principle of dialectical approach to pedagogical phenomena based on the inconsistency of the object or phenomenon studied, interrelationship and interdependence of quantitative and qualitative changes.

4. The principle of unity of the logical and historical, which requires that each research should combine studying the history of the object (the genetic aspect), its theory (the links of the object in its current state) and its development prospects.

5. The principle of the unity of the educational process, determining the concept of learning.

6. The principle of systematic study of the process in accordance with all its requirements, especially the requirement of the holistic approach to the research of the process. This, in its turn, determined the choice of the main methods for achieving the goal:

- methods of the empirical level: observation, comparison, counting, measurement, questionnaire, interview, tests, trial and error method, etc.;

- methods of experimental and theoretical level: experiment, analysis and synthesis, induction and deduction, modeling, hypothetical, historical, and logical methods;

- methods of theoretical level: abstraction, idealization, formalization, analysis and synthesis, induction and deduction, axiomatics, generalization, etc.

\section{CONCLUSION}

Positioning the university on the educational services market involves the following: creating the image of a competitive university as a member of networking; using complementary assets of universities - network partners; implementing network educational programs, and opening basic departments (and other 
institutions) as the university brands which confirm its leading role in the education system .of Russia.

Implementation of this idea primarily involves interdisciplinary, social and philosophical understanding of the phenomenon under study, the outcome of which is to result in the construction of a theoretical and methodological foundation for the analysis and designing models of partnership networks (with the university participation) ; optimization of activity in the social networks, evaluation of the effectiveness and prediction of the consequences of partnership networking of universities. This will allow finding out and using the opportunities offered by social-networks, opening new prospects for the innovative development of universities which arise from the dynamics of the network processes of social interaction among the leading higher educational institutions and scientific fields.

Traditional methods of teaching at the University do not provide the currently required quality of professional training and need further developing in many areas: improving all forms of the University management , revising of the curricula and programmes (Zaburdaeva 2013; 2014 Zaburdaeva; Kazantseva \& Zaburdaeva \& Kolyago 2015), improving textbooks, planning students' research work, etc. The experience of organizing an network interaction, developing the algorithm of implementing the virtual academic mobility between universities will give an opportunity to constantly update the teaching knowledge in accordance with the latest scientific achievements, because the present education system is often focused more on the education of a future scientist- theorist rather than on training a practicing professional.

\section{REFERENCE LIST}

Andreeva, I.N., \& Glizerina, N.D., \& Kolomiets, D.L., \& Kurochkina, L.V., \& Maltseva, E.V., \& Shestakova, O.B. (2015).Technologies of Organizing Prospective Teachers' Practical Training on the Basis of Competence Approach, Review of European Studies. Vol. 7 (8), pp. 43-51.

Kazantseva, I.V., \& Zaburdaeva, T.I., \& Kolyago, A.L. (2015). Assessment of Test Quality in German for Bachelor Students on the Basis of Common European Competences in Foreign Language // Mediterranean Journal of Social Sciences. Vol 6 (3). pp. 381-387.

http://www.mcser.org/journal/index.ph...e/view/167 Doi:10.5901/mjss.2015.v6n3s7p381

Zaburdaeva, T.I. (2013). The algorithm of working out grammar tests on the basis of the handbook standard "Profile Deutsch". XXI century: Results of the Past and Problems of the Present+, (8), pp.187-193. Penza: Penza State Technological Academy.

Zaburdaeva, T.I. (2014). Perfecting tests used as the means of educational measurements on the basis of Common European Framework of Reference for Languages. Foreign Languages: Linguistic and Methological Aspects, (26), pp.59-65. Tver: Tver State University.

Zaburdaeva, T.I., \& Serebryakova, M.A., \& Kazantseva, I.V., \& Kolyago, A.L., \& Ivanova, O.V. (2015). Control of Competences Formation of Foreign Language Bachelor Students on the Basis of LMS Moodle // Review of European Studies. Vol. 7 (8). pp. 295-307. http://dx.doi.org/10.5539/res.v7n8p295

Zaburdaeva, T.I, \& Kazantseva, I.V., \& Kolyago, A.L., \& Shestakova, O.B., \& Hammelmann, M.M. (2016).

Linguodidactic Testology: An Assessment Methodology of Professional Competencies Formation of Foreign Languages Faculty Bachelor Students. The Social Sciences 11 (8), pp. 1747-1752. ISSN 1818-5800. Medwell Journal. DOI: 10.3923/sscience.2016.1747.1752 